\title{
Dietary Walnuts Protect Against Obesity-Driven Intestinal Stem Cell Decline and Tumorigenesis
}

\section{Fangxia Guan ${ }^{1,2,3}$, Tahmineh Tabrizian ${ }^{1,4}$, Ardijana Novaj ${ }^{1,4}$, Masako Nakanishi ${ }^{5}$, Daniel W. Rosenberg ${ }^{5}$ and Derek M. Huffman ${ }^{1,2,4 *}$}

${ }^{1}$ Department of Molecular Pharmacology, Albert Einstein College of Medicine, Bronx, NY, United States, ${ }^{2}$ Department of Medicine, Albert Einstein College of Medicine, Bronx, NY, United States, ${ }^{3}$ School of Life Sciences, Zhengzhou University, Zhengzhou, China, ${ }^{4}$ Institute for Aging Research, Albert Einstein College of Medicine, Bronx, NY, United States, ${ }^{5}$ School of Medicine, University of Connecticut Health, Farmington, CT, United States

Obesity can negatively impact intestinal homeostasis, and increase colon cancer risk and related mortality. Thus, given the alarmingly high rates of obesity in the US and globally, it is critical to identify practical strategies that can break the obesity-cancer link. Walnuts have been increasingly recognized to mitigate cancer risk, and contain many bioactive constituents with antioxidant and anti-inflammatory properties that could potentially counteract pathways thought to be initiators of obesity-related cancer. Therefore, the purpose of this study was to determine if walnuts could preserve intestinal homeostasis, and attenuate tumorigenesis and growth in the context of obesity and a high calorie diet. To this end, we studied effects of walnuts on these parameters under different dietary conditions in wildtype mice, two independent $A p c$ models $\left(A p c^{1638 \mathrm{~N} /+}\right.$ and $\left.A p c^{\Delta 14}\right)$, and in MC38 colon cancer cells in vivo, respectively. Walnuts did not alter the metabolic phenotype or intestinal morphology in normal mice fed either a low-fat diet (LFD), LFD with $6 \%$ walnuts (LFD+W), high-fat diet (HFD), or HFD with $7.6 \%$ walnuts $(\mathrm{HFD}+\mathrm{W})$. However, walnuts did lead to a significant reduction in circulating CCL5 and preserved intestinal stem cell (ISC) function under HFD-fed conditions. Furthermore, walnuts reduced tumor multiplicity in $A p c^{1638 \mathrm{~N} /+}$ male HFD+W animals, as compared to HFD controls $(3.7 \pm 0.5$ vs. $2.5 \pm 0.3 ; P=0.015)$, tended to reduce the number of adenocarcinomas (0.67 \pm 0.16 vs. $0.29 \pm 0.12 ; P=0.07)$, and preferentially limited tumor growth in $A p c^{\Delta 14}$ male mice $(P=0.019)$ fed a high-calorie western-style diet. In summary, these data demonstrate that walnuts confer significant protection against intestinal tumorigenesis and growth and preserve ISC function in the context of a high-calorie diet and obesity. Thus, these data add to the accumulating evidence connecting walnuts as a potentially effective dietary strategy to break the obesity-colon cancer link.

Keywords: colon cancer, obesity, walnuts, inflammation, intestine

\section{INTRODUCTION}

Obesity is a major risk factor for colon cancer, as well as accelerated disease progression (1) and related mortality $(2,3)$. Indeed, a meta-analysis of prospective studies determined that an elevated body mass index (BMI>30) increases the risk for this disease by $30-70 \%$ in men, but less so in women (4). While general obesity (BMI) is clearly linked to colon cancer risk, the distribution 
of body fat appears to be even more revealing, as surrogate measures of abdominal obesity more strongly predict colon cancer risk in both men and women (5), and we have shown that this link is causal in a mouse model (6). While the role of excess weight on cancer risk is apparent, the hazards posed by obesity on cancer mortality are even more striking, and is nearly universal among the most common forms of cancer, including an increased risk of death from colon cancer by $46 \%$ in women and by nearly two-fold in men $(2,7)$.

Recently, it has become clear that the ramifications of obesity on intestinal homeostasis can be observed well before the onset of tumor formation, with marked effects on tissue morphology (8), function (9), and a "molecular signature" which may "prime" intestinal cells toward a more tumorigenic predisposition (10), increasing tumor incidence and progression in the presence of an oncogenic insult. Indeed, we and others have shown a marked increase in tumor incidence within the context of obesity, utilizing either $A p c$ mutant mice (6) or azoxymethane (AOM) treatment $(11,12)$, to initiate tumor development in rodents. Likewise, pre-clinical models have demonstrated that obesity accelerates tumor growth and metastatic disease. Given the alarmingly high rates of obesity in the US and globally, and its clear link to cancer, it is critical to identify practical strategies that can break this link.

Walnuts (Juglans regia), which are well known to promote cardiovascular health, have also been reported to reduce risk for type 2 diabetes, cognitive decline, and all-cause mortality (13-16). Indeed, walnuts contain many bioactive constituents, including omega-3 fats (i.e., ALA), $\curlyvee$-tocopherol, phytosterols and several polyphenolic compounds that harbor anti-oxidant and anti-inflammatory properties (17). More recently, a growing number of reports have documented cancer protective effects of walnuts and its components in cells as well as in animal models of prostate, breast and colon cancer (18-25). Indeed, early studies in colon cancer cells documented cytotoxic and pro-apoptotic effects of individual walnut components, while an initial study in mice demonstrated that a walnut-supplemented diet significantly slowed the growth of HT-29 human colon cancer cells in vivo (17). These effects were attributed to a suppression of angiogenesis and alterations in the miRNA expression and fatty acid composition of tumor cells $(26,27)$. More recently, walnut consumption was demonstrated to reduce tumor burden in an AOM model of colon cancer selectively in male mice (24). Interestingly, walnut consumption was also linked to alterations in the microbial community structure associated with reduced tumor progression (24), which was corroborated by a study in Fischer 344 rats, which demonstrated increased abundance of Firmicutes with reduced abundance of Bacteriodetes (28).

As obesity has been shown to accelerate intestinal tumor formation and progression $(6,9,29-32)$, practical dietary strategies centered on natural foods to mitigate this risk are warranted. Given the documented beneficial effects of walnuts on the gut, coupled with its potential to counteract many risk factors thought to define the obesity-cancer link, the purpose of this study was to understand to what extent, if any, walnuts harbor the ability to preserve intestinal homeostasis, and attenuate intestinal tumorigenesis and growth in the context of obesity and a high calorie diet.

\section{MATERIALS AND METHODS}

\section{Experimental Diets}

Fresh shelled walnuts were provided by the California Walnut Commission. For diet production, walnuts were shipped to Envigo (formerly Harlan, Madison, WI) where they were ground on site and incorporated into appropriate experimental diets and soft-vacuum packed into $1 \mathrm{~kg}$ bags to preserve freshness. A total of four pelleted diets were generated for this study: a control low-fat diet (LFD), an isocaloric LFD in which walnuts were incorporated at $6 \%$ by weight $(\mathrm{LFD}+\mathrm{W})$, a control high fat diet (HFD), and an isocaloric HFD containing 7.67\% walnuts by weight $(\mathrm{HFD}+\mathrm{W})$. The walnut content for the HFD was adjusted to account for the anticipated reduction in food intake for mice consuming more energy dense food. The detailed diet formulations are shown in Table 1. Walnut doses were chosen based upon prior studies in rodents which have found these amounts to be most beneficial for cancer prevention (24) and attenuation of behavioral deficits in Alzheimer's Disease models (33). Diets were routinely replaced with fresh pellets twice per week and individual bags were only used for up to 2 weeks after breaking the vacuum seal. In addition, a total western diet (TWD) containing either $0 \%$ or $7 \%$ walnuts was also utilized for a parallel study in $A p c^{\Delta 14}$ mice (24). All experimental animals were housed and treated in accordance with protocols reviewed and approved by the Institute for Animal Care and Use Committee at the Albert Einstein College of Medicine (Protocol \#20150103) and the Center for Comparative Medicine (CCM) at UConn Health (Protocol \#101369-0519), respectively.

\section{Experiment 1 Design: Intestinal Phenotyping}

Three week-old male C57BL/6J mice were obtained from The Jackson Labs (Bar Harbor, ME) for general phenotyping and intestinal characterization studies. Animals were housed in the animal facility at Einstein, kept under standard conditions and provided ad libitum access to food and water. After 1 week of

TABLE 1 | Dietary formulations of control and walnut-supplemented low fat and high fat diets.

\begin{tabular}{lcccc}
\hline Component $(\mathbf{g} / \mathbf{k g})$ & LFD & LFD+W & HFD & HFD+W \\
\hline Casein & 210 & 200 & 245 & 231.75 \\
Sucrose/Corn Starch & $90 / 465$ & $90 / 455$ & $200 / 85$ & $200 / 85$ \\
Maltodextrin & 100 & 100 & 115 & 102 \\
Walnuts, \% & 0 & 6 & 0 & 7.6 \\
Lard and Soybean Oil & $20 / 20$ & $0.45 / 0.45$ & $195 / 30$ & $146 / 30$ \\
Kcal from CHO, \% & 69.1 & 69.1 & 36.0 & 36.0 \\
Kcal from Protein, \% & 20.5 & 20.5 & 19.0 & 19.0 \\
Kcal from Fat, \% & 10.4 & 10.4 & 45.0 & 45.0 \\
Kcal/g & 3.6 & 3.6 & 4.6 & 4.6
\end{tabular}


acclimatization, mice were single housed and assigned to either LFD, LFD+W, HFD or HFD+W ( $n=12$ per group). Body weight was monitored weekly and food intake was measured twice per week until 24 weeks of age. Body composition was evaluated at 22 weeks of age by quantitative magnetic resonance (qMR Echo MRI). After 20 weeks on diet, insulin sensitivity was evaluated by insulin tolerance tests (ITT) at a dose of 1 $\mathrm{mU} / \mathrm{kg}$ insulin by intraperitoneal (i.p.) injection in random fed mice. At study completion, animals were fasted $4 \mathrm{~h}$ and sacrificed for collection of plasma and tissues for biochemical assays. In addition, the gastrointestinal tract was carefully and rapidly excised and staged as a Swiss roll for paraffin embedding and histopathologic analysis.

\section{Experiment 2 Design: Intestinal Tumorigenesis in Apc ${ }^{1638 N /+}$ Mice}

$A p c^{1638 \mathrm{~N} /+}$ male mice on a C57BL/6 background and female C57BL/6J mice (Jackson Labs, Bar Harbor, ME) were mated to generate $A p c^{1638 \mathrm{~N} /+}$ male offspring. We have previously used this mutant model to demonstrate that obesity and specifically visceral fat, is implicated in tumor development of these mice (6). This model also has the benefit of a significant latency in pathology, with tumor initiation beginning around 4 months of age and most animals demonstrating tumor burden by 68 months of age. At 4 weeks of age, $A p c^{1638 \mathrm{~N} /+}$ male mice were assigned to either LFD $(n=11), \mathrm{LFD}+\mathrm{W}(n=12)$, HFD $(n=18)$ or HFD $+\mathrm{W}$ groups $(n=23$ group). Animals assigned to LFD groups were then followed for up to 32 weeks of age and animals assigned to the HFD groups were followed for up to 24 weeks of age. A power analysis, based upon our prior study (6), determined a sample size of $n=18$ per group would be necessary to detect a $25 \%$ reduction in tumor multiplicity with $80 \%$ statistical power. While these numbers were achieved in the HFD study, the number of LFD animals in which pathologic data was collected at the study endpoint was underpowered in relation to our target sample size, due to some premature mortality in these groups. At necropsy, the entire intestine was quickly excised, surrounding mesenteric fat removed, and the gut divided into duodenum, jejunum, ileum and colon, as previously described (6). Each segment was opened longitudinally, rinsed in ice-cold phosphate-buffered saline, and carefully flattened for examination of tumor multiplicity with the aid of a dissecting, magnifying lens. Adenomas ( $>0.5 \mathrm{~mm}$ diameter $)$ when present, were counted in each segment of intestinal tissue and recorded.

\section{Experiment 3 Design: Intestinal Tumorigenesis in $A p c^{\Delta 14}$ Mice}

Beginning at 4 weeks of age, $A p c^{\Delta 14}$ mice were fed the TWD (Harlan Laboratories) supplemented with $0 \%$ or $7 \%$ walnuts by weight, and the composition of these diet formulations have been described previously (24). Male (Con TWD $n=12$, TWD $+7 \%$ Walnut $n=11$ ) and female (Con TWD $n=10$, TWD $+7 \%$ Walnut $n=9$ ) mice were provided the experimental diets for 12 weeks and then animals were sacrificed and intestinal tissue excised and processed as described earlier (24), for assessment of tumor incidence and growth throughout the gastrointestinal tract.

\section{Experiment 4 Design: Colon Cancer Cell Progression}

In order to determine whether walnuts can protect against more advanced disease, 8 week-old male C57BL/6J mice $(n=48)$ were obtained from The Jackson Labs and group housed 4 per cage. Following a 1 week acclimation, animals were assigned to either LFD, LFD+W, HFD or HFD+W diets ( $n=12$ group) for approximately 12 weeks. Tumor progression was then evaluated using an established tumor inoculation protocol by injection of MC38 cells (a kind gift of Shoshana Yakar) into the right rear flank $\left(0.5 \times 10^{6} \mathrm{MC} 38\right.$ cells $)$ of syngeneic C57BL/6J mice. Tumor volume was then monitored over 19 days with calipers and calculated by the equation $\mathrm{V}=\mathrm{L} \times \mathrm{W}^{2} \times 0.5$, where $\mathrm{L}$ is length and $\mathrm{W}$ is width of the tumor (34), and tumor weights were recorded at sacrifice. A tumor length and width measuring in excess of $1.25 \mathrm{~cm}$, evidence of ulceration at the tumor sight, or a body condition score $<2$ were considered humane endpoints during the study. Some animals met or exceeded the tumor size criteria by day 19 and the study was immediately terminated at this point. MC38 cells were maintained in Dulbecco's Modified Eagle Medium (DMEM) containing $1 \mathrm{mM}$ sodium pyruvate, $2 \mathrm{mM}$ L-glutamine and $1 \mathrm{mM}$ non-essential amino acid and supplemented with $10 \%$ fetal bovine serum (FBS) (GIBCO, USA), at $37^{\circ} \mathrm{C}$ in the presence of $5 \% \mathrm{CO}_{2}$. Obesity was previously shown to increase growth and proliferation of MC38 cells following injection (35), establishing this model as an ideal tool to test for effect of walnuts on cancer progression.

\section{Morphometric Analysis}

Evaluation of the gastrointestinal tract was performed following isolation and division into four segments: duodenum, jejunum, ileum and colon, as previously described $(6,36)$. Tissues were rolled and fixed overnight in $10 \%$ neutral-buffered formalin at $4^{\circ} \mathrm{C}$, processed through a series of alcohols and xylenes, and embedded in paraffin. Hematoxylin \& Eosin (H\&E) stained sections $(5 \mu \mathrm{m})$ from each segment of small intestine were then scanned into digital files with a PerkinElmer P250 High Capacity Slide Scanner, and crypt area and villi length were evaluated in Panoramic Viewer using 50 random villi per animal to form a single composite average.

\section{Western Blotting}

Western blotting was performed as described (37). Protein was extracted from frozen tissues in RIPA buffer and total protein content was determined using the BCA protein assay (Sigma, St. Louis, Mo) with BSA as a standard. Proteins were separated by SDS-PAGE, transferred onto PVDF membranes and incubated with an appropriate primary and secondary antibody. Equal loading and transfer was confirmed by staining, imaging and quantifying the original gel, using Biorad stain-free gel technology. Immunoblotting was performed for pS6 (\#5364), total S6 (\#2217), pAkt Ser473 (\#4060), total Akt (\#4691), pp44/42MAPK ${ }^{\text {Thr202/Tyr204 }}$ (\#9101) total p44/42 MAPK (\#4695), and $\beta$-catenin (\#8480), all from Cell Signaling. Bands were 
visualized by chemiluminescence to first indication of pixel saturation using a Biorad Chemidoc bioimager and densitometry performed using Image Lab 4.1 (Biorad, Hercules, CA).

\section{Gene Expression in Colon and Small Intestine}

Total RNA from frozen tissues was isolated using the Trizol procedure as described previously (36). In brief, first-strand complementary DNA (cDNA) was synthesized with random primers and total RNA as a template using Biorad iScript cDNA Synthesis Kit. All qPCR reactions were carried out using Biorad Sso Advanced SYBR Green mix on a Biorad CFX384 qRT-PCR Machine. All data were then normalized to the housekeeping gene, 18S, using the delta delta Ct method. Primer sequences are provided in Supplementary Table 1.

\section{Plasma Measures}

Whole blood was collected following a $4 \mathrm{~h}$ fast into K2-EDTA collection tubes (Sarstedt AG \& Co; Numbrect, Germany), and plasma was separated from red blood cells by centrifugation $\left(1,500 \times \mathrm{g}, 4^{\circ} \mathrm{C}, 15 \mathrm{~min}\right)$. Plasma free fatty acids (Wako Diagnostics, Richmond, VA, USA) and triglycerides (Sigma, St. Louis, MO) were analyzed using standard calorimetric assays. Plasma insulin levels were measured by a rat/mouse ELISA (EMD Millipore, Inc.) with rat insulin standards using a spectrophotometer (Biorad iMark platereader) following the manufacturer's instructions $(36,37)$. In addition, a Bio-Plex MAGPIX Multiplex Reader (Biorad Inc., Hercules, CA) was used to measure the following 23 inflammatory mediators simultaneously in plasma: Eotaxin, G-CSF, GM-CSF, IFN- $\gamma$, IL10, IL-12 (p40), IL-12 (p70), IL-13, IL-15, IL-17, IL-1 $\alpha$, IL-1 $\beta$, IL-2, IL-3, IL-4, IL-5, IL-6, IL-7, IL-9, IP-10, KC, LIF, LIX, MCSF, MCP-1, MIG, MIP-1 $\alpha$, MIP-1 $\beta$, MIP-2, RANTES, TNF- $\alpha$, and VEGF.

\section{Adipose Tissue Cytokine Array}

Protein was extracted from epididymal fat in PBS buffer with Triton X-100 and protease inhibitors (Roche). Total protein content was determined using the BCA protein assay as above (Sigma, St. Louis, Mo) with BSA as a standard. $250 \mathrm{ug}$ of total protein was applied to the membrane array and protein levels of 40 cytokines/chemokines were quantified according to the manufacturer's instructions (R\&D Systems, Inc., Minneapolis, MN). Specific factors measured in this assay included: CXCL13, C5a, G-CSF, GM-CSF,I-309, Eotaxin, sICAM-1, IFN- $\gamma$, IL-1 $\alpha$, IL-1 $\beta$, IL-1ra, IL-2, IL-3, IL-4, IL-5, IL-6, IL-7, IL-10, IL-13, IL-12p70, IL-16, IL-17, IL-23, IL-27, IP-10, I-TAC, KC, M-CSF, JE, MCP-5, MIG, MIP-1 $\alpha$, MIP$1 \beta$, MIP-2, RANTES, SDF-1,TARC, TIMP-1, TNF- $\alpha$, TREM1.

\section{Intestinal Permeability}

To determine intestinal barrier function, animals were fasted for $4 \mathrm{~h}$ and then gavaged ( $n=10$ /group) and evaluated with the well-described 4,000 Da fluorescent dextran-FITC assay (DX4000-FITC; Sigma-Aldrich, St. Louis, Missouri, USA) (38-40). Specifically, mice were fasted for a minimum of $4 \mathrm{~h}$ and then dosed with DX-4000-FITC by gavage ( $500 \mathrm{mg} / \mathrm{kg}$ body weight, $125 \mathrm{mg} / \mathrm{ml}$ ). After $4 \mathrm{~h}, \sim 50 \mathrm{uL}$ of blood was collected via tail bleed and plasma isolated. For measurement, plasma was diluted 1:1 in PBS ( $\mathrm{pH} 7.4$ ) and analyzed for FITC with a fluorescence reader ( $485 \mathrm{~nm}$ excitation and $535 \mathrm{~nm}$ ) against a standard curve as described (41).

\section{Intestinal Organoid Assay}

In order to assess intestinal stem cell (ISC) function, crypts were isolated from the small intestine of LFD, HFD and HFD+W fed mice ( $n=4$ group) following 4 weeks on diet, as previously described $(36,42)$. Isolated crypts were washed with $\mathrm{ADF}$ medium, centrifuged at $800 \mathrm{rpm}$ for $5 \mathrm{~min}$, re-suspended in ADF medium and counted on a hemocytometer. Approximately 250 crypts were then re-suspended in $25 \mathrm{uL}$ of matrigel, transferred to a 48 -well plate to solidify at $37^{\circ} \mathrm{C}$ for $30 \mathrm{~min}$, and overlaid with 250 ul crypt culture medium (ADF 1x, Pen/Strep 1x, HEPES 1x, Glutamax 1x, N2 1x, B27 1x, N-acetyl-L-cysteine 1 $\mu \mathrm{M}$, Noggin $100 \mathrm{ng} / \mathrm{ml}$, EGF $50 \mathrm{ng} / \mathrm{ml}$, Rock inhibitor $10 \mu \mathrm{M}$, and R-Spondin $500 \mathrm{ng} / \mathrm{ml}$ ) and maintained at $37^{\circ} \mathrm{C}$. Fresh medium was applied every 3 days and the number and organoid formation on day 9 was assessed with a light microscope and normalized to the beginning number of counted crypts and expressed as organoids per crypt.

\section{Statistics}

Parametric cross-sectional data were log- transformed to ensure normality of distribution and analyzed by either independent samples t-test, one-way or two-way ANOVA (diet x walnut) with Tukey post-hoc adjustment when appropriate, while longitudinal measurements were assessed by repeated measures ANOVA, using SPSS v16 (SPSS, Chicago, IL). For non-parametric data, or when normality could not be achieved, data were analyzed by the Kruskal-Wallis procedure, and post-hoc comparisons performed using the Mann-Whitney $U$-test. $P \leq 0.05$ was considered significant.

\section{RESULTS}

\section{Dietary Walnuts Do Not Significantly Affect the Metabolic Phenotype}

We first set out to characterize the phenotypic effects of walnuts on the metabolic phenotype when exposed to LFD and HFD conditions. As shown in Figure 1A, HFD-fed mice were heavier than LFD-fed animals, and weight gain was not mitigated by walnuts under either condition. LFD $+\mathrm{W}$ mice consumed more food than LFD controls (Figure 1B; $P<0.05$ ), but intake was similar between HFD and HFD $+\mathrm{W}$ groups (Figure 1B). However, FFAs and TGs were not significantly different among groups (Figures 1C,D). We next performed ITTs in random-fed mice (1 mU/kg dose) and also evaluated insulin levels after a $4 \mathrm{~h}$ fast. Overall, no significant difference in insulin sensitivity (Figure 1E) or insulin levels (Figure 1F) were observed among groups, though HFD mice tended to have higher insulin levels and more impaired insulin sensitivity than other groups. HFD per se also increased adiposity (Figure 1G), without impacting lean mass (Figure 1H), including a significant increase in visceral fat 

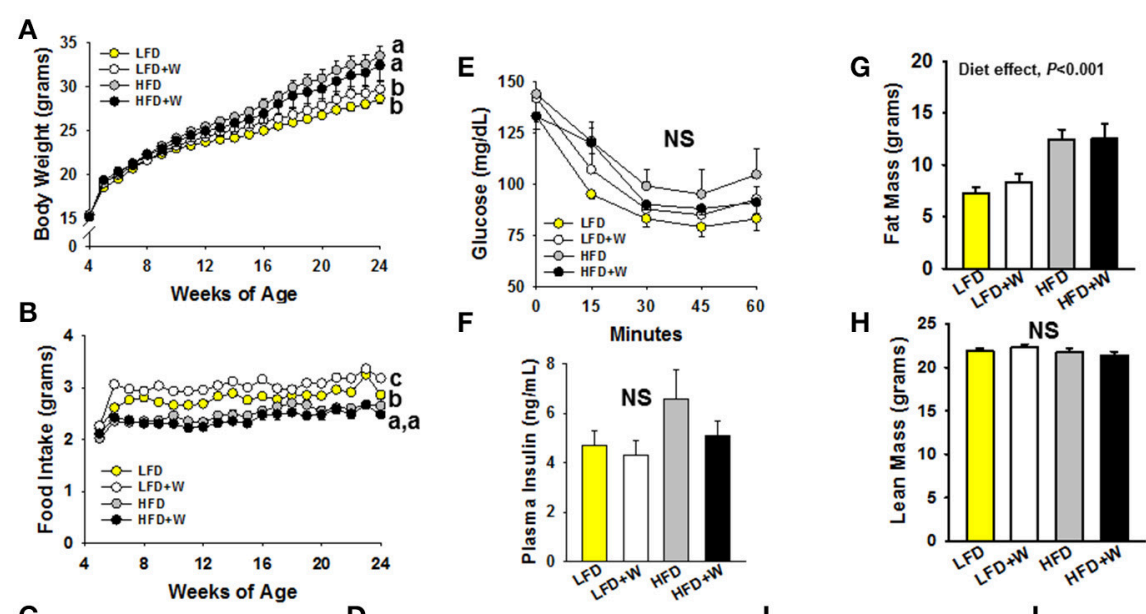

$\mathbf{F}$

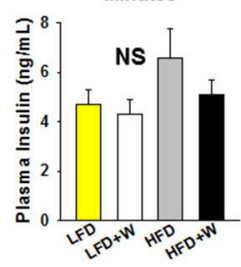

$\mathbf{H}$

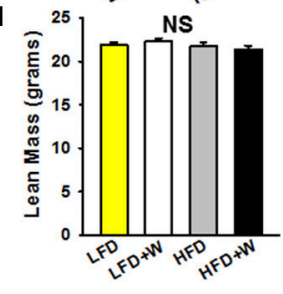

C
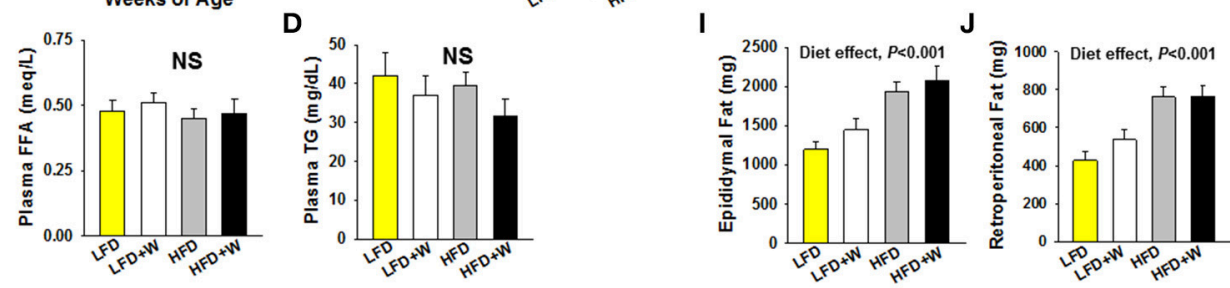

FIGURE 1 | Effect of diet and walnut consumption on the metabolic phenotype in male C57BL/6J mice. (A) Mice fed a HFD were significantly heavier than LFD-fed counterparts, irrespective of walnut intake. (B) Mice consuming the LFD $+W$ demonstrated a significant increase in food intake as compared to controls, while no difference was observed between HFD and HFD+W mice. (C,D) No significant effects of diet or walnut intake was observed for plasma FFA or TG levels $(n=12$ per group) (E,F) Results of an ITT suggest no significant effects on insulin sensitivity, though HFD mice tended to be more resistant and hyperinsulinemic than other groups ( $n=11-12$ per group). (G-J) HFD groups were fatter than LFD-fed animals, including an increase in visceral fat, without effects of walnuts, while lean mass was similar across groups. Bars represent mean \pm SE. NS, Not significant. Different letters denote a significant difference between groups, $P \leq 0.05$.

(Figures 1I,J; Diet effect $=P<0.001$ ), and these effects were not moderated by walnuts.

\section{Walnuts Preserve Intestinal Stem Cell Function Under HFD Conditions}

We next examined the role of walnuts in the context of LFD and HFD conditions, on intestinal morphology, mucosal barrier integrity and ISC function. In both jejunum and ileum, we observed no effect of HFD or walnut intake on crypt area or villi length (Figures 2A-D). Interestingly, tight junction-related genes in jejunum were upregulated in LFD+W mice, with exception of ZO-1, but not in HFD+W animals (Figures 2E-H), while no differences were observed in colon (Supplementary Figure 1). In addition, we assessed intestinal membrane permeability in vivo, as determined by the appearance of FD4 in plasma (Figure 2I). In contrast to prior reports of increased intestinal "leak" with HFD, we observed only a marginal increase in plasma FITC from HFD-fed animals, and this parameter was not significantly altered by walnuts. Finally, we employed an ex vivo 3D intestinal organoid assay, previously used to demonstrate increased ISC proliferation by caloric restriction and rapamycin (42), and reduced function with aging. Following 4 weeks on a HFD, we observed a significant reduction in the ability of ISCs to generate organoidlike structures (Figure 2J). However, this decline in ISC function with HFD was completely prevented by walnuts $(P<0.05)$.

\section{Walnuts Reduce Systemic but Not Tissue Levels of Inflammation}

In order to characterize the inflammatory status of experimental animals, we first profiled plasma levels of cytokines and chemokines using a multiplex format. Among 23 analytes profiled, MIP- $1 \alpha$ was reduced in both HFD groups, while only CCL 5 was reduced in HFD $+\mathrm{W}$ mice, as compared to all other groups (Table 2; $P<0.05$ ). At the tissue level, expression of TNF $\alpha$ in jejunum tended to be decreased with HFD or HFD+W feeding, which was significant for IL-1 $\beta$ (Figures 3A,B; Diet effect $=P<0.05$ ), while no differences were observed in colon (Figures 3C,D). Meanwhile, a protein array in visceral adipose tissue determined that walnuts and HFD per se downregulated $\mathrm{C} 5$ levels, while other inflammatory markers were up-regulated with high-fat feeding, including IL-1ra, and CCL2 (Diet effect $=P<0.001$ ), whereas IL-23 was increased only in HFD $+\mathrm{W}$ mice $(P<0.05)$, suggesting that walnuts did not interfere with adipose-related inflammation in obesity (Figures 3E-I).

\section{Walnuts Tend To Preserve Gut Metabolic Signaling While Reducing $\beta$-Catenin Levels}

We next assessed metabolic signaling pathways related to intestinal homeostasis, including NF- $\mathrm{B}$, Akt and $\beta$-catenin. In jejunum, we observed that high-fat feeding per se significantly 

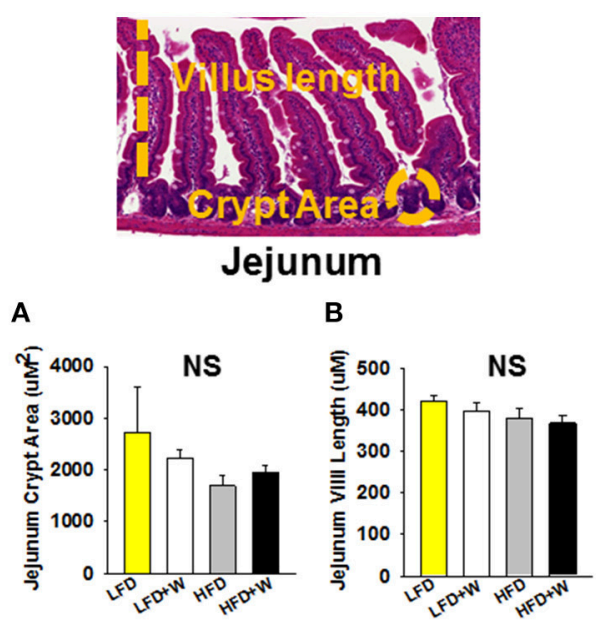

\section{Ileum}
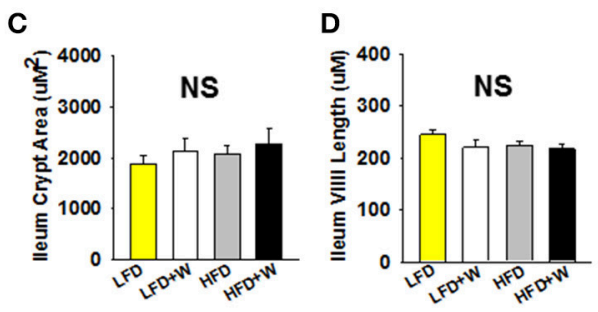
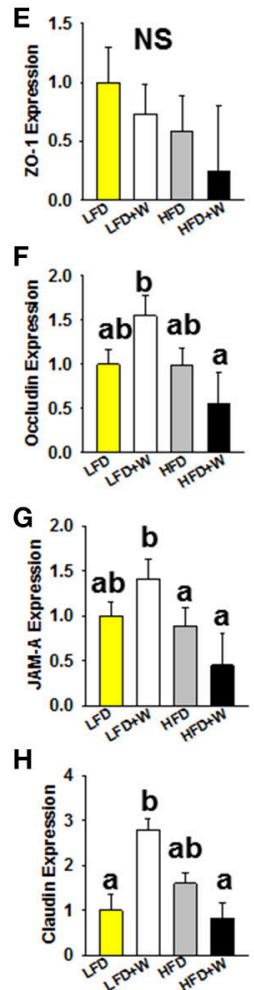
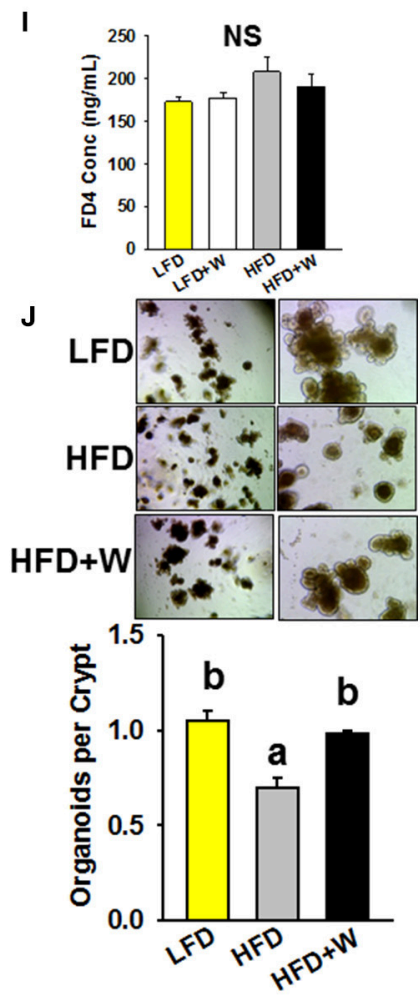

FIGURE 2 | Effect of diet and walnut consumption on features of intestinal status and function. (A-D) Morphometric analysis revealed no significant difference in crypt area or villus length in jejunum or ileum ( $n=9-12$ per group). (E-H) Gene expression of intestinal tight junction-related genes in jejunum suggest that walnuts supplemented in the LFD upregulated occludin, JAM-A and claudin expression ( $n=10$ per group). (I) Measurement of intestinal leak in vivo using the FD4 assay revealed no significant difference in intestinal permeability among groups ( $n=10$ per group). (J) ISC function, as determined by an ex vivo organoid formation assay at day 9 , revealed a significant impairment in organoid generation with HFD, but this reduction was prevented by inclusion of walnuts ( $n=3$ per group). Bars represent mean \pm SE. NS, Not significant. Different letters denote a significant difference between groups, $P \leq 0.05$.

reduced total NF-кB (Figure 4A; Diet effect $=P<0.05$ ), but not pS6 (Figure 4B), and significantly increased pErk (Diet effect $=P<0.001$ ), with a concomitant reduction in total Erk (Diet effect $=P<0.01$ ) and $\beta$ catenin (Figures 4C,D; Diet effect $=P$ $<0.05$ ). Meanwhile, pAkt levels, which were numerically reduced in HFD mice, tended to be maintained in the HFD+W animals, but this did not reach significance (Figure 4E). In contrast, most metabolic signaling measures in colon were unaffected by HFD or walnuts, with the exception of a significant reduction in pErk in the HFD group, which was completely prevented by walnuts (Supplementary Figure 1; $P<0.05$ ).

\section{Walnuts Protect Against Obesity-Driven Intestinal Tumorigenesis, but Not Progression}

Consistent with observations in wild type mice, no difference in body weight was observed over 28 weeks of study (32 weeks old) in $A p c^{1638 \mathrm{~N} /+}$ male mice fed either a LFD (Figure 5A) or 20 weeks of study (24 weeks old) in the HFD-fed groups (Figure 5B), respectively, regardless of walnut supplementation. Furthermore, no significant difference was observed in small intestinal adenoma formation between LFD or LFD+W fed mice
(Figure 5C; $P=0.71$ ), though it should be acknowledged that the sample size of these groups were somewhat limited in power, as compared to the HFD study. On the other hand, HFD-fed mice demonstrated accelerated tumor development and increased multiplicity, as compared to LFD cohorts, necessitating the truncation of the study to 24 weeks in these mice. Remarkably, walnuts potently mitigated tumor formation in HFD-fed $A p c^{1638 \mathrm{~N} /+}$ males, reducing tumor burden by approximately $32 \%$ (Figure 5D; $3.7 \pm 0.5$ vs. $2.5 \pm 0.3 ; P=0.01$ ). We further performed histopathology on intestinal tissues from the HFD cohort and observed a tendency toward reduced tubulovillous adenomas $(P=0.14)$ and adenocarcinomas $(P=0.07)$ in $\mathrm{HFD}+\mathrm{W}$ mice (Table 3 ).

In order to further confirm the protective effects of walnuts on tumorigenesis within the context of an unhealthy diet, we next performed a study in $A p c^{\Delta 14 /+}$ male and female mice, using an established TWD paradigm, which we have previously used to demonstrate a protective effect of walnuts in the AOM colon cancer model (24). Inclusion of walnuts in the TWD had no effect on weight gain in either males or females (Figures 6A,B), which is consistent with other data on weight gain. Further, no effect on tumor multiplicity was observed in the small intestine for either sex (Figure 6C), but a slight numerical reduction in colon 
TABLE 2 | Inflammatory cytokines and chemokines in male C57BL/6J mice provided either a control or walnut-supplemented low fat or high fat diet.

\begin{tabular}{|c|c|c|c|c|}
\hline Analyte (pg/mL) & LFD $(n=9)$ & LFD+W $(n=10)$ & HFD $(n=10)$ & HFD+W $(n=10)$ \\
\hline $\mathrm{IL}-1 \alpha$ & $44.9 \pm 5.1$ & $40.0 \pm 6.5$ & $67.1 \pm 33.5$ & $27.0 \pm 5.2$ \\
\hline $\mathrm{IL}-1 \beta$ & $562.5 \pm 60.4$ & $436.1 \pm 60.2$ & $403.9 \pm 59.1$ & $479.5 \pm 119.1$ \\
\hline IL-2 & $56.8 \pm 10.7$ & $49.0 \pm 8.9$ & $56.8 \pm 10.7$ & $34.1 \pm 9.1$ \\
\hline IL-3 & $19.6 \pm 3.6$ & $15.7 \pm 3.9$ & $13.4 \pm 3.4$ & $9.0 \pm 3.7$ \\
\hline IL-4 & $9.2 \pm 3.1$ & $12.3 \pm 3.1$ & $8.5 \pm 2.3$ & $12.8 \pm 4.5$ \\
\hline IL-5 & $40.2 \pm 5.1$ & $30.0 \pm 6.7$ & $25.8 \pm 6.1$ & $34.9 \pm 8.8$ \\
\hline IL-6 & $22.4 \pm 3.8$ & $14.5 \pm 2.0$ & $11.8 \pm 3.0$ & $12.7 \pm 2.7$ \\
\hline IL-9 & ND & ND & ND & ND \\
\hline IL-10 & $125.1 \pm 15.2$ & $86.2 \pm 22.1$ & $80.1 \pm 20.1$ & $53.4 \pm 17.2$ \\
\hline IL-12 (p40) & $461.0 \pm 126.4$ & $341.4 \pm 13.6$ & $269.4 \pm 19.8$ & $282.3 \pm 29.5$ \\
\hline IL-12 (p70) & $220.1 \pm 30.2$ & $167.0 \pm 41.6$ & $205.6 \pm 52.1$ & $106.3 \pm 32.0$ \\
\hline $\mathrm{IL}-13$ & $309.6 \pm 65.9$ & $263.8 \pm 53.8$ & $218.5 \pm 53.8$ & $166.8 \pm 56.4$ \\
\hline IL-17 & $66.0 \pm 13.5$ & $55.8 \pm 18.6$ & $81.3 \pm 25.4$ & $32.6 \pm 10.1$ \\
\hline CCL-11 & $1898.9 \pm 171.7$ & $1447.0 \pm 230.8$ & $1253.4 \pm 264.1$ & $922.9 \pm 234.8$ \\
\hline G-CSF & $79.7 \pm 5.7$ & $67.2 \pm 5.4$ & $92.1 \pm 11.8$ & $87.9 \pm 18.3$ \\
\hline GM-CSF & $310.8 \pm 41.7$ & $238.6 \pm 45.6$ & $227.2 \pm 45.9$ & $144.5 \pm 50.0$ \\
\hline CXCL-1 & $84.4 \pm 13.4$ & $64.0 \pm 5.9$ & $61.4 \pm 5.6$ & $70.8 \pm 13.4$ \\
\hline MCP-1 & $474.0 \pm 69.7$ & $397.9 \pm 74.4$ & $331.8 \pm 86.2$ & $267.0 \pm 73.7$ \\
\hline $\mathrm{MIP}-1 \alpha$ & $31.4 \pm 1.8^{a}$ & $32.3 \pm 2.8^{a b}$ & $24.9 \pm 2.4^{b}$ & $23.7 \pm 3.8^{b}$ \\
\hline MIP-1 $\beta$ & $112.3 \pm 15.0$ & $82.2 \pm 19.2$ & $70.3 \pm 20.6$ & $52.1 \pm 17.4$ \\
\hline CCL5 & $48.1 \pm 3.5^{a}$ & $46.9 \pm 7.0^{\mathrm{a}}$ & $40.3 \pm 4.9^{a}$ & $23.1 \pm 3.9^{b}$ \\
\hline $\mathrm{IFN} \curlyvee$ & $81.9 \pm 11.5$ & $81.2 \pm 17.4$ & $62.5 \pm 17.2$ & $37.7 \pm 10.6$ \\
\hline TNF- $\alpha$ & $600.8 \pm 79.8$ & $488.5 \pm 107.5$ & $434.1 \pm 118.9$ & $324.0 \pm 91.0$ \\
\hline
\end{tabular}

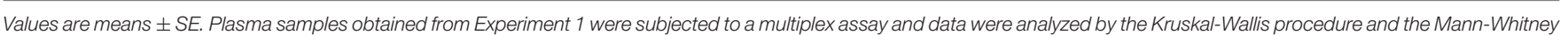

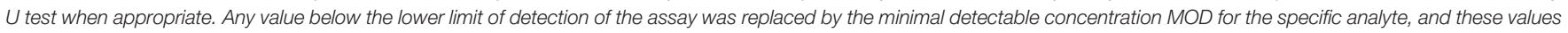
were ranked as a tie for purposes of the statistical analysis. Different letters denote a significant difference between groups for MIP-1a and CCL5 respectively, P $\leq 0.05$.

tumor number was observed in males (Figure 6D), which was accompanied by a significant reduction in colon tumor volume in males only (Figure 6E; $P=0.019$ ). However, this was not associated with changes in proliferation markers, including Ki67 and $\beta$ catenin staining by IHC (Supplementary Figure 2).

Finally, we evaluated the effect of walnuts on colon cancer cell progression in male C57BL/6J mice. Following the injection of tumor cells, palpable tumors were detected by day 7 and tumor volume was monitored for 19 days after injection. Tumor growth, based upon volume measurements, tended to be greater in HFD and HFD $+\mathrm{W}$ mice by day 19 , as compared to LFD groups, but did not reach statistical significance (Figure 7A). However, tumor weight was significantly greater in HFD mice, as compared to LFD controls $(P<0.05)$, while tumor weight tended to be greater in LFD+W mice, as compared to their respective controls (Figure 7B). Furthermore, in contrast to the protective effects of walnuts conferred on obesity-accelerated tumorigenesis, growth was not mitigated in HFD+W mice, suggesting walnuts do not confer protection in lean or obese animals against MC38 cancer cell progression in vivo.

\section{DISCUSSION}

It has been proposed that cancer development is an inevitable consequence of multiple stem cell divisions and stochastic processes that provoke DNA damage, increasing the probability for tumorigenesis (43). However, an extensive body of evidence has strongly implicated environmental and other lifestyle factors as significant modulators of cancer risk, including colon cancer (44). Obesity has proven to be particularly hazardous for cancer risk at many sites, as well as accelerated disease progression and related mortality $(2,3)$. Such evidence is alarming given that more than two-thirds of US adults are now overweight or obese $(45,46)$, and obesity rates are expected to remain a major health concern despite public health efforts to reverse this trend. In fact, based upon current estimates of obesity and its probable health consequences, it is estimated that 65 million more US adults will be obese by 2030, resulting in 492,000-669,000 new cancer cases in the US alone (47). Therefore, simple and cost-effective strategies are urgently needed that can break the obesity-cancer link.

Over the past several decades, nut consumption generally, and dietary walnuts specifically, have proven beneficial for aspects of human health, including improved lipid profiles (16, $48,49)$ and endothelial function, while epidemiologic studies have linked walnut intake with reduced incidence of type 2 diabetes, cognitive decline, and cardiovascular disease-related mortality (13-16). More recently, several preclinical and in vitro studies have uncovered beneficial effects of walnuts and its components on cancer risk (17), particularly in colon cancer models $(24,26,27,50-52)$. Given that walnuts are enriched with a complex composition of bioactives that could interfere with the 


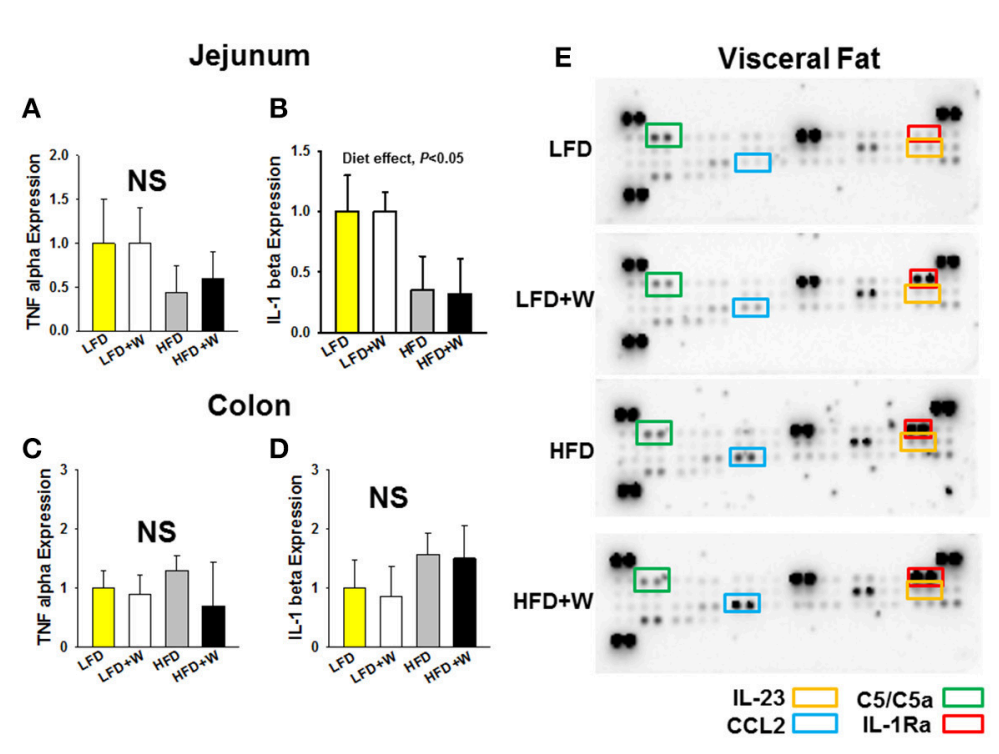

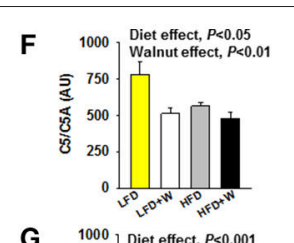

G

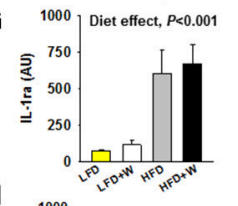

H

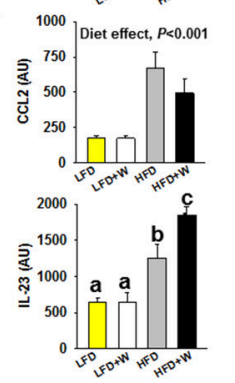

FIGURE 3 | Effect of diet and walnut consumption on intestinal and adipose tissue inflammation. (A-D) Gene expression for TNF $\alpha$ and IL-1 $\beta$ in jejunum and colon failed to detect a significant change in inflammatory gene expression with HFD feeding or an effect of walnuts. To the contrary, a main effect of diet was observed in jejunum, indicating a reduction in cytokine expression by HFD per se, irrespective of walnuts ( $n=10$ per group). (E-I) Using a cytokine array in adipose tissue, a significant reduction in C5/C5a was observed with walnut diets, while IL-1ra and CCL2 were increased in both HFD and HFD+W groups ( $n=4$ per group). On the other hand, IL-23 levels were markedly elevated only in the HFD+W group. Bars represent mean \pm SE. NS, Not significant. Different letters denote a significant difference between groups, $P \leq 0.05$.
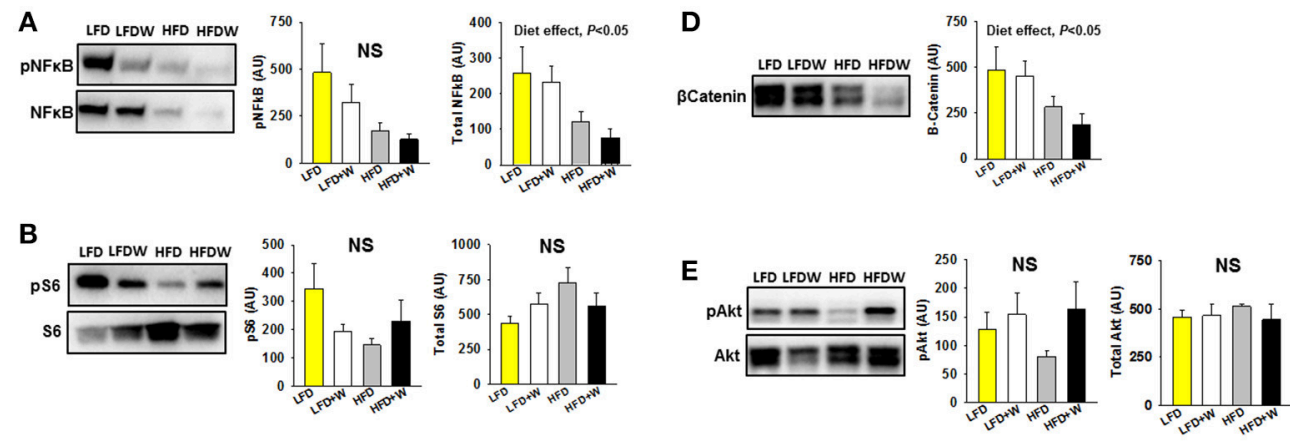

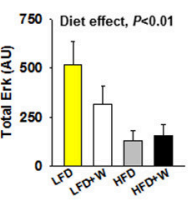

FIGURE 4 | Effect of diet and walnut consumption on intestinal metabolic signaling pathways. (A) In jejunum, we observed a tendency for reduced pNFKB (p65) in HFD and HFD+W animals, while a significant diet effect was observed for total NFKB ( $n=8$ per group). (B) Both walnuts and HFD tended to reduce pS6, which sits downstream of various growth factor signaling pathways and the mTOR pathway. (C,D) High-fat feeding significantly increased pErk, with a concominant reduction in total Erk and $\beta$-catenin. (E) While not significant, pAkt levels tended to be reduced in HFD mice and better maintained in HFD+W animals. Bars represent mean \pm SE. NS, Not significant. There were no signficant diet $x$ walnut interactions among groups.

tumor-promoting effects of the obese environment, we reasoned that they could prove particularly efficacious in mitigating obesity-related cancer risk. Consistent with our hypothesis, we show in two independent $A p c$ models of intestinal cancer, that walnuts confer protective effects against tumor incidence and growth, and that these effects appear to be most prominent under metabolic duress, as no such effect was observed when animals were provided a LFD. However, these benefits appear to be limited to tumor initiation and promotion, as we failed to observe any protective effect of walnuts on MC38 colon cancer 

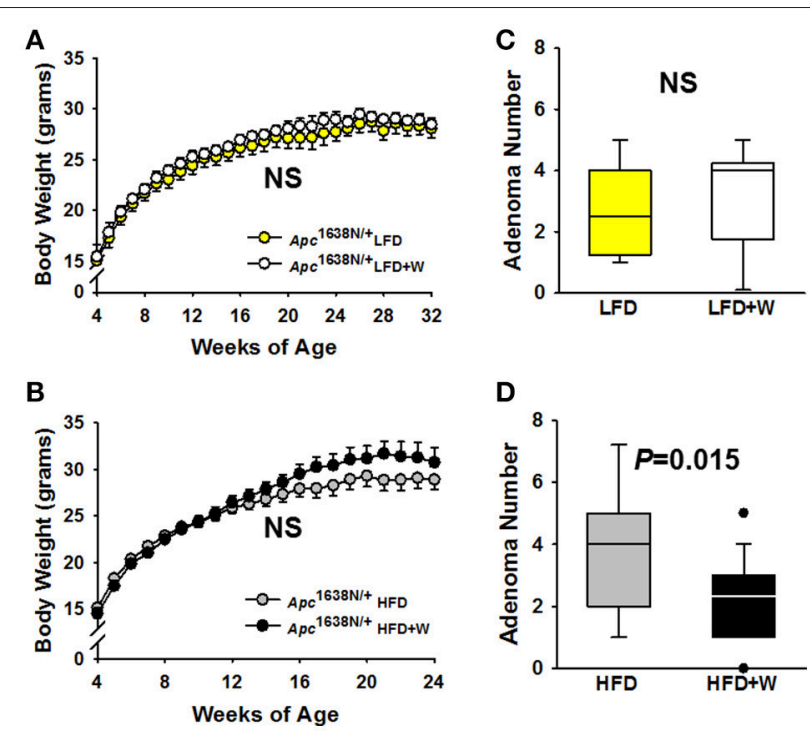

FIGURE 5 | Effect of diet and walnut consumption on intestinal tumorigenesis in $A p c^{1638 N /+}$ male mice. Tumorigenesis was evaluated in Apc ${ }^{1638 N /+}$ male mice on a control or walnut-supplemented LFD for up to 32 weeks of age [LFD $(n=11), \mathrm{LFD}+\mathrm{W}(n=12)]$, while a second cohort was provided either a control or walnut-supplemented HFD for up to 24 weeks of age [HFD $(n=18)$, HFD+W groups ( $n=23$ group)]. (A,B) Similar to results in wild type mice, walnuts did not alter weight gain on the LFD or HFD, respectively, over the course of the study. (C) At 32 weeks of age, post-mortem analysis revealed no significant differences in small intestinal tumor multiplicity, as determined by the number of adenomas between LFD and LFD+W mice. (D) In contrast to the LFD experiment, tumor numbers were significantly reduced in HFD+W animals, as compared to HFD controls ( $P=0.015)$, which is supported by histopathologic analysis shown in Table 3 . Lines and symbols represent mean \pm SE. Box plots indicate median values and first to third quartile range, while lines indicate minimum and maximum range; symbols indicate outliers. NS, Not significant.

cell growth rates in vivo, either under low or high fat dietary conditions. The latter results are in contrast to a prior study reporting an inhibitory effect of walnut consumption on HT29 colon cancer cell growth in inoculated mice (26), which was attributed to decreased angiogenesis and altered miRNA and fatty acid profiles in the tumor cells (27). Thus, while the evidence linking walnuts to reduced tumorigenesis appears to be increasingly robust, their ability to slow colon cancer progression is less clear and would benefit not only from additional studies, but also from better models that more closely recapitulate the pathophysiology of human metastatic disease.

A second important observation from these studies is that the benefits of walnuts on tumor growth appear to be sexually dimorphic, with preferential protection conferred in male mice, which is in agreement with a previous study on walnuts and colon cancer (24). Sex differences are now well-recognized to play a major role in responses to various pharmacologic interventions on lifespan and healthspan (53), as well as in the etiology of many diseases, including colon cancer. Indeed, a meta-analysis of prospective studies determined that an elevated body mass index (BMI > 30) increases the risk for colon cancer by $30-70 \%$ in men, but less so in women $(4,54)$. This sex difference was also apparent
TABLE 3 | Histopathology of the gastrointestinal tract in Apc ${ }^{1638 N /+}$ mice provided either a control or walnut-supplemented high fat diet.

\begin{tabular}{llll}
\hline & HFD $(\boldsymbol{n}=\mathbf{1 8})$ & HFD+W $(\boldsymbol{n}=\mathbf{1 6})$ & $\boldsymbol{P}$-value \\
\hline $\begin{array}{l}\text { Hyperplasia, crypt } \\
\text { epithelial, Focal }\end{array}$ & $1.16 \pm 0.35$ & $1.08 \pm 0.34$ & 0.87 \\
$\begin{array}{l}\text { Hyperplasia, crypt } \\
\text { epithelial, Multifocal }\end{array}$ & $1.22 \pm 0.11$ & $1.17 \pm 0.12$ & 0.77 \\
$\begin{array}{l}\text { Dysplastic foci } \\
\text { Adenoma, tubular }\end{array}$ & $0.39 \pm 0.14$ & $0.52 \pm 0.21$ & 0.63 \\
$\begin{array}{l}\text { Adenoma, tubulovillous } \\
\text { Total Adenoma }\end{array}$ & $0.61 \pm 0.18$ & $0.53 \pm 0.21$ & 0.77 \\
Adenocarcinoma, tubular & $0.33 \pm 0.11$ & $0.12 \pm 0.08$ & 0.14 \\
Adenocarcinoma, & $0.33 \pm 0.14$ & $0.18 \pm 0.10$ & 0.32 \\
tubulovillous & & $0.64 \pm 0.22$ & 0.19 \\
Total Adenocarcinoma & $0.67 \pm 0.16$ & $0.29 \pm 0.12$ & 0.07 \\
\hline
\end{tabular}

Values are means $\pm S E$. No differences were observed between HFD and HFD+W mice on crypt hyperplasia or occurrence of disyplastic foci. Consistent with an observed decrease in adenoma formation by gross examination, HFD $+W$ mice tended to have a reduction in tubulovillous adenoma formation, and a trend for reduced adenocarcinoma development, $P=0.07$. "Value based on the pathologic severity using a 1-4 scale, with 4 being most severe.

in a large prospective study (European Prospective Investigation into Cancer and Nutrition; EPIC) (55), which found that the risk of colon cancer was $55 \%$ greater in the highest quintile of BMI, as compared to the lowest quintile in men, but no association was observed in women (5). Interestingly, the risk of colon cancer in women increases after menopause and is modulated by hormone replacement, highlighting an important protective role for sex hormones in the pathophysiology of this disease (56). Thus, the presumably high levels of female sex hormones during tumor development in these mice may have obscured any protective effect of walnuts on tumorigenesis. Future studies interrogating the effect of walnuts and other interventions on intestinal cancer should account for hormonal status as a potential modifier of the response.

Although the ability of walnuts to mitigate intestinal tumors, particularly in obesity, is now well demonstrated, the mechanism(s) underlying this protection are not entirely clear. Metabolic dysfunction, including insulin resistance, along with the chronic low-grade pro-inflammatory state typical of obesity, are commonly cited as major drivers of obesity-related cancers (57), and we reasoned that walnuts could potentially interfere with one or more of these processes. However, we were unable to detect such effects of walnuts on any metabolic parameters tested, although in HFD $+\mathrm{W}$ we did observe a marked reduction in plasma CCL5 levels, and this cytokine has been linked to colon cancer growth and progression (58-60). Meanwhile, consistent with many observations, adipose inflammation was markedly increased in HFD-fed mice, irrespective of walnut intake, suggesting that a reduction in adipose inflammation is not a mechanism linking walnuts to reduced tumorigenesis in these mice.

Beyond potential systemic mediators of the cancerpreventative effects of walnuts, the proximity of walnut digestion and absorption to the gut suggests a high probability 

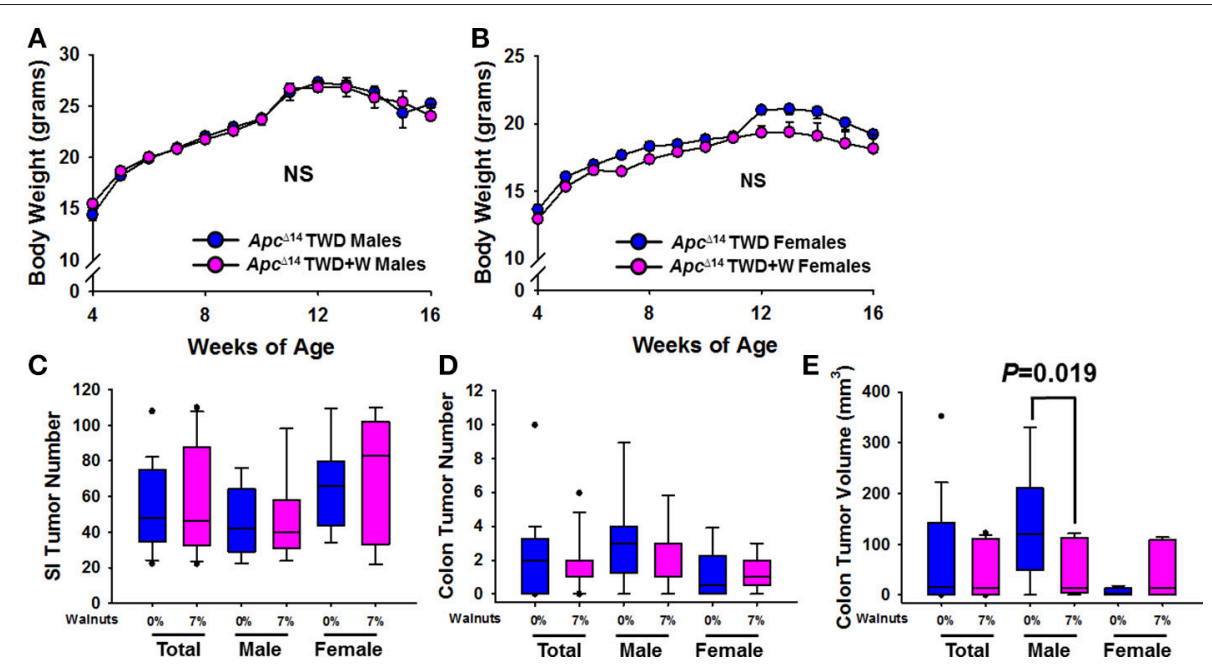

FIGURE 6 | Effect of diet and walnut consumption on intestinal tumorigenesis in Apc $\Delta 14 /+$ male and female mice. Tumorigenesis was studied in a second mouse model of intestinal tumorigenesis $\left(A p c^{\Delta 14 /+}\right.$ ). Male (Con TWD $n=12$, TWD $+7 \%$ Walnut $\left.n=11\right)$ and female (Con TWD $n=10$, TWD+7\% Walnut $n=9$ ) mice were provided either a control TWD or TWD supplemented with $7 \%$ walnuts, a dose range in which we have previously determined to confer optimal protection against tumorigenesis. (A,B) There was no effect of walnuts on weight gain with TWD in either male or female mice, further supporting that walnuts do not alter energy balance in mice. (C,D) Tumor latency and multiplicity is more severe in the Apc ${ }^{\Delta 14 /+}$ mouse than in Apc1638 animals, but tumor multiplicity was not significantly different between groups in either sex. (E) When average tumor volume was determined in the colon, size was significantly reduced only in male mice $(P=0.019)$. Lines and symbols represent mean \pm SE. Box plots indicate median values and first to third quartile range, while lines indicate minimum and maximum range; symbols indicate outliers. NS, Not significant.

that direct inhibition of tumor growth or other alterations to the gut environment are involved in the attenuation of tumor growth by dietary walnuts. Indeed, several studies have demonstrated that individual components contained in walnuts, including $\alpha$-linolenic acid (ALA), $\gamma$-tocopherol, carotenoids, and polyphenols, all harbor the ability to retard cancer cell growth in vitro and in vivo (17). Walnuts also contain significant amounts of fiber, which has been associated with a modest reduction in colorectal cancer risk in some reports (61-63). More recently, two rodent studies have demonstrated that dietary walnuts can significantly and favorably modulate the composition of the gut microbiome $(24,28)$, including an increase in microbial diversity and enrichment for more probiotic-type bacteria including Firmicutes, Lactobacillus, Ruminococcaceae, and Roseburia, and a reduction Bacteroides and Anaerotruncus, and these shifts in structure have been associated with less colon cancer risk. Further, if alterations to the gut microbiome are indeed involved in retarding tumor development and growth, this may explain in part why walnuts failed to slow colon cancer cell progression in the xenograft model, in which MC38 cells were implanted into the animal's flank, entirely removed from the normal gut microenvironment.

A final consideration relates to how the experimental diets were designed, which involved rigorously matching for calories and macronutrient composition. Achieving this level of control in the HFD formulas required among other adjustments, reducing saturated fat content in the form of lard by $\sim 25 \%$ in the HFD+W formulation, to account for the fat content in walnuts. Thus, we cannot completely rule out that this modest displacement in fat and/or other nutrient sources could have contributed to some of the protective effects in the HFD+W

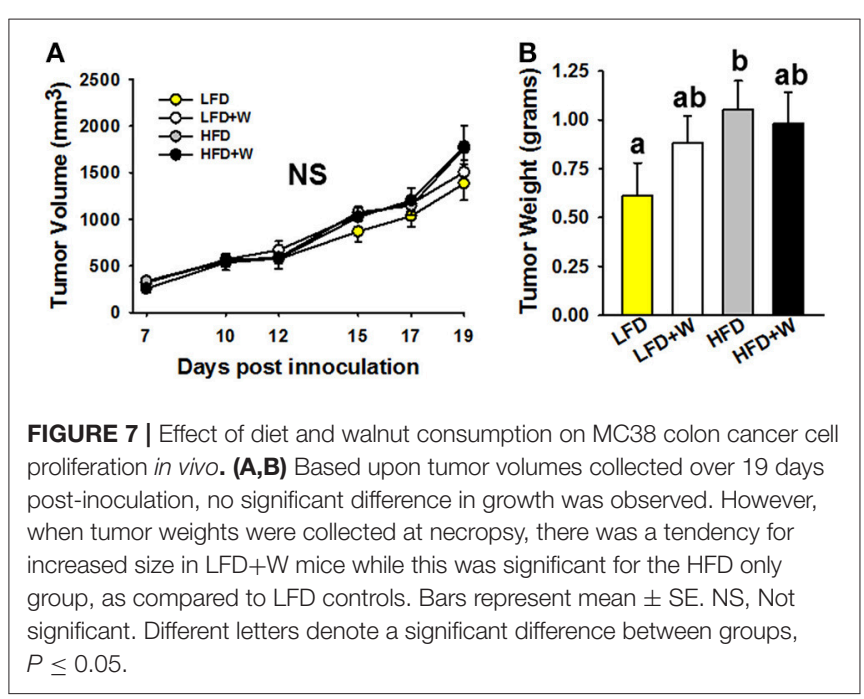

group, though this seems unlikely, as lard content in this diet still remained exceedingly high, as compared to the LFD formula. Furthermore, while red meat intake is generally associated with colon cancer $(64,65)$, the association between saturated fat per se and colon cancer risk in humans is somewhat controversial $(66,67)$, while evidence in rodents supports both increased (68) and decreased risk for colon cancer risk by saturated fat (69).

Since the discovery of specific ISC populations, including Lgr5+, Bmi1+, or Lrig1+ ISCs (70-72), and their ability to serve as the origin of intestinal tumor development, much interest has been focused on their function in the context of diet and aging. 
Obesity per se has also been shown to induce hypertrophy of the intestinal mucosa (8), changes to the colonic epigenomic landscape that favor growth (10), increased ISC proliferation, stemness, and accelerated tumor development in Apc-deficient Lgr5+-ISCs (9). However, ISC function has also been shown to be impaired in aging (73), while the age-delaying strategies, rapamycin and caloric restriction, boost ISC function (42). Here, we observed impaired ISC function in young mice on a HFD, while ISC proliferation, as determined by organoid formation, was markedly maintained by walnut supplementation. While the exact functional relevance of this effect on ISC function will require further study, it provides an intriguing example of how walnuts are able to preserve a key aspect of intestinal homeostasis in obesity.

As previously mentioned, a HFD was previously shown to promote ISC proliferation and stemness, effects that were proposed to correlate with the increased proliferative potential of gut stem-cell derived cancers in obesity (9). However, we observed a contrasting result, whereby obesity impaired ISC function that was preserved by walnuts. While a definitive explanation of these disparate results is not entirely clear, an important distinction between our approach (36) and others (9), is that our HFD-fed animals are compared to a carefullymatched, low fat purified diet, rather than a poorly-defined chowbased formula. The contrasting compositions of purified vs. chow based formulations, and the ability of multiple individual components in chow diet to impact intestinal function and tumorigenesis, independent of calories, has been extensively discussed elsewhere $(36,74)$.

In summary, these data demonstrate that walnuts confer significant protection against intestinal tumorigenesis and growth in the context of obesity and a high-calorie diet. Previous studies have linked various mechanisms to the protective effects of walnuts in colon cancer, including alterations to the microbiome, and we further noted reductions in circulating CCL5 in HFD mice supplemented with walnuts, though changes in tissue inflammation or metabolic signaling did not seem to be impacted by walnuts. Furthermore, these data demonstrate that even prior to tumor initiation, walnuts preserve aspects of intestinal homeostasis by mitigating the impairment in ISC function imposed by a HFD. Thus, these findings, along with prior observations, strongly suggest that walnuts can serve as a potentially-effective dietary strategy to break the obesity-colon cancer link, a possibility which should be further explored in human trials.

\section{REFERENCES}

1. Dignam JJ, Polite BN, Yothers G, Raich P, Colangelo L, O'Connell MJ, et al. Body mass index and outcomes in patients who receive adjuvant chemotherapy for colon cancer. J Natl Cancer Inst. (2006) 98:1647-54. doi: $10.1093 /$ jnci/djj442

2. Calle EE, Rodriguez C, Walker-Thurmond $\mathrm{K}$, and Thun MJ. Overweight, obesity, and mortality from cancer in a prospectively studied cohort of U.S. adults. N Engl J Med. (2003) 348:1625-38. doi: 10.1056/NEJMoa021423

\section{ETHICS STATEMENT}

All experimental animals were housed and treated in accordance with protocols reviewed and approved by the Institute for Animal Care and Use Committee at the Albert Einstein College of Medicine (Protocols \#20150103) and the Animal Care Committee at the University of Connecticut Health Center, respectively. Data were rigorously collected by several team members, repeated when necessary, and were summarized, reviewed, and approved by all authors without bias, fabrication or data manipulation.

\section{AUTHOR CONTRIBUTIONS}

$\mathrm{DH}$ and DR contributed to the conception and design of the study, data analysis and interpretation, and wrote and edited the manuscript. FG and MN designed experiments, developed methodologies, performed experiments, and wrote and edited the manuscript. TT and AN contributed to experimental design, development of methodology, performed the experiments and edited the manuscript.

\section{ACKNOWLEDGMENTS}

This work was supported by the NIA (R56AG052981; R21AG055026), the American Institute for Cancer Research (AICR) and the California Walnut Commission. The authors would also like to acknowledge the NCI supported Einstein Cancer Center (P30CA013330), the Einstein Nathan Shock Center for Excellence in the Biology of Aging (P30AG038072), and the Einstein-Sinai Diabetes Research Center (P30DK20541). Experiments performed in the Einstein Analytical Imaging Core were supported by an NIH SIG award (\#1S10OD019961-01). TT is supported by a T32 Training Grant (T32AG23475). The content provided in this manuscript does not necessarily represent the official views of the AICR and the California Walnut Commission and is solely the responsibility of the authors with no input on interpretation or reporting of findings by the sponsors.

\section{SUPPLEMENTARY MATERIAL}

The Supplementary Material for this article can be found online at: https://www.frontiersin.org/articles/10.3389/fnut.2018. 00037/full\#supplementary-material is an independent prognostic variable in colon cancer survivors. Clin Cancer Res. (2010) 16:1884-93. doi: 10.1158/1078-0432.CCR-09-2636

4. Giovannucci E. Metabolic syndrome, hyperinsulinemia, and colon cancer: a review. Am J Clin Nutr. (2007) 86:s836-42. doi: 10.1093/ajcn/86.3.836S

5. Pischon T, Lahmann PH, Boeing H, Friedenreich C, Norat T, Tjonneland A, et al. Body size and risk of colon and rectal cancer in the European Prospective Investigation Into Cancer and Nutrition (EPIC). J Natl Cancer Inst. (2006) 98:920-31. doi: 10.1093/jnci/djj246 
6. Huffman DM, Augenlicht LH, Zhang X, Lofrese JJ, Atzmon G, Chamberland $\mathrm{JP}$, et al. Abdominal obesity, independent from caloric intake, accounts for the development of intestinal tumors in $\mathrm{Apc}(1638 \mathrm{~N} /+)$ female mice. Cancer Prev Res. (Phila) (2013) 6:177-87. doi: 10.1158/1940-6207.CAPR-12-0414

7. Kim H, and Giovannucci EL. Sex differences in the association of obesity and colorectal cancer risk. Cancer Causes Control (2017) 28:1-4. doi: 10.1007/s10552-016-0831-5

8. Mao J, Hu X, Xiao Y, Yang C, Ding Y, Hou N, et al. Overnutrition stimulates intestinal epithelium proliferation through beta-catenin signaling in obese mice. Diabetes (2013) 62:3736-46. doi: 10.2337/db13-0035

9. Beyaz S, Mana MD, Roper J, Kedrin D, Saadatpour A, Hong SJ, et al. High-fat diet enhances stemness and tumorigenicity of intestinal progenitors. Nature (2016) 531:53-8. doi: 10.1038/nature17173

10. Li R, Grimm SA, Chrysovergis K, Kosak J, Wang X, Du Y, et al. Obesity, rather than diet, drives epigenomic alterations in colonic epithelium resembling cancer progression. Cell Metab. (2014) 19:702-11. doi: 10.1016/j.cmet.2014.03.012

11. Chen J, and Huang XF. High fat diet-induced obesity increases the formation of colon polyps induced by azoxymethane in mice. Ann Transl Med. (2015) 3:79. doi: 10.3978/j.issn.2305-5839.2015.03.46

12. Velazquez KT, Enos RT, Carson MS, Cranford TL, Bader JE, Chatzistamou I, et al. Weight loss following diet-induced obesity does not alter colon tumorigenesis in the AOM mouse model. Am J Physiol Gastrointest Liver Physiol. (2016) 311:G699-712. doi: 10.1152/ajpgi.00207.2016

13. Ros E. Nuts and novel biomarkers of cardiovascular disease. Am J Clin Nutr. (2009) 89:1649S-56S. doi: 10.3945/ajcn.2009.26736R

14. Tapsell LC, Batterham MJ, Teuss G, Tan SY, Dalton S, Quick CJ, et al. Long-term effects of increased dietary polyunsaturated fat from walnuts on metabolic parameters in type II diabetes. Eur J Clin Nutr. (2009) 63:1008-15. doi: $10.1038 /$ ejen.2009.19

15. Pan A, Sun Q, Manson JE, Willett WC, and Hu FB. Walnut consumption is associated with lower risk of type 2 diabetes in women. J Nutr. (2013) 143:512-8. doi: 10.3945/jn.112.172171

16. Kris-Etherton PM. Walnuts decrease risk of cardiovascular disease: a summary of efficacy and biologic mechanisms. J Nutr. (2014) 144:547S-54S. doi: 10.3945/jn.113.182907

17. Hardman WE. Walnuts have potential for cancer prevention and treatment in mice. J Nutr. (2014) 144:555S-60S. doi: 10.3945/jn.113.188466

18. Lee KS, Li G, Kim SH, Lee CS, Woo MH, Lee SH, et al. Cytotoxic diarylheptanoids from the roots of Juglans mandshurica. J Nat Prod. (2002) 65:1707-8. doi: 10.1021/np0201063

19. Reiter RJ, Tan DX, Manchester LC, Korkmaz A, Fuentes-Broto L, Hardman $\mathrm{WE}$, et al. A walnut-enriched diet reduces the growth of LNCaP human prostate cancer xenografts in nude mice. Cancer Invest. (2013) 31:365-73. doi: 10.3109/07357907.2013.800095

20. Kim H, Yokoyama W, Davis PA. TRAMP prostate tumor growth is slowed by walnut diets through altered IGF-1 levels, energy pathways, and cholesterol metabolism. J Med Food (2014) 17:1281-6. doi: 10.1089/jmf.2014.0061

21. Sanchez-Gonzalez C, Ciudad CJ, Noe V, Izquierdo-Pulido M. Walnut polyphenol metabolites, urolithins $\mathrm{A}$ and $\mathrm{B}$, inhibit the expression of the prostate-specific antigen and the androgen receptor in prostate cancer cells. Food Funct. (2014) 5:2922-30. doi: 10.1039/C4FO00542B

22. Sanchez-Gonzalez C, Ciudad C, Noe V, Izquierdo-Pulido M. Health benefits of walnut polyphenols: an exploration beyond their lipid profile. Crit Rev Food Sci Nutr. (2015) 57:3373-83. doi: 10.1080/10408398.2015.1126218

23. Hayes D, Angove MJ, Tucci J, and Dennis C. Walnuts (Juglans regia) chemical composition and research in human health. Crit Rev Food Sci Nutr. (2016) 56:1231-41. doi: 10.1080/10408398.2012.760516

24. Nakanishi M, Chen Y, Qendro V, Miyamoto S, Weinstock E, Weinstock GM, et al. Effects of walnut consumption on colon carcinogenesis and microbial community structure. Cancer Prev Res. (Phila) (2016) 9:692-703. doi: 10.1158/1940-6207.CAPR-16-0026

25. Sun ZL, Dong JL, Wu J. Juglanin induces apoptosis and autophagy in human breast cancer progression via ROS/JNK promotion. Biomed Pharmacother. (2017) 85:303-12. doi: 10.1016/j.biopha.2016.11.030

26. Nagel JM, Brinkoetter M, Magkos F, Liu X, Chamberland JP, Shah $S$, et al. Dietary walnuts inhibit colorectal cancer growth in mice by suppressing angiogenesis. Nutrition (2012) 28:67-75. doi: 10.1016/j.nut.2011 03.004

27. Tsoukas MA, Ko BJ, Witte TR, Dincer F, Hardman WE, and Mantzoros CS, Dietary walnut suppression of colorectal cancer in mice: mediation by miRNA patterns and fatty acid incorporation. J Nutr Biochem. (2015) 26:776-83. doi: 10.1016/j.jnutbio.2015.02.009

28. Byerley LO, Samuelson D, Blanchard ET, Luo M, Lorenzen BN, Banks S, et al. Changes in the gut microbial communities following addition of walnuts to the diet. J Nutr Biochem. (2017) 48:94-102. doi: 10.1016/j.jnutbio.2017. 07.001

29. Gravaghi C, Bo J, Laperle KM, Quimby F, Kucherlapati R, Edelmann W, et al. Obesity enhances gastrointestinal tumorigenesis in Apc-mutant mice. Int $J$ Obes (Lond). (2008) 32:1716-9. doi: 10.1038/ijo.2008.149

30. Hata K, Kubota M, Shimizu M, Moriwaki H, Kuno T, Tanaka T, et al. C57BL/KsJ-db/db-Apc mice exhibit an increased incidence of intestinal neoplasms. Int J Mol Sci. (2011) 12:8133-45. doi: 10.3390/ijms121 18133

31. Pettan-Brewer C, Morton J, Mangalindan R, and Ladiges W. Curcumin suppresses intestinal polyps in APC Min mice fed a high fat diet. Pathobiol Aging Age Relat Dis. (2011) 1:7013. doi: 10.3402/pba.v1i0.7013

32. Day SD, Enos RT, McClellan JL, Steiner JL, Velazquez KT, Murphy EA. Linking inflammation to tumorigenesis in a mouse model of high-fat-diet-enhanced colon cancer. Cytokine (2013) 64:454-62. doi: 10.1016/j.cyto.2013.04.031

33. Muthaiyah B, Essa MM, Lee M, Chauhan V, Kaur K, Chauhan A. Dietary supplementation of walnuts improves memory deficits and learning skills in transgenic mouse model of Alzheimer's disease. J Alzheimers Dis. (2014) 42:1397-405. doi: 10.3233/JAD-140675

34. Harvey AE, Lashinger LM, Otto G, Nunez NP, and Hursting SD. Decreased systemic IGF-1 in response to calorie restriction modulates murine tumor cell growth, nuclear factor-kappaB activation, and inflammation-related gene expression. Mol Carcinog (2013) 52:997-1006. doi: 10.1002/mc. 21940

35. Yakar S, Nunez NP, Pennisi P, Brodt P, Sun H, Fallavollita L, et al. Increased tumor growth in mice with diet-induced obesity: impact of ovarian hormones. Endocrinology (2006) 147:5826-34. doi: 10.1210/en.2006-0311

36. Tabrizian T, Wang D, Guan F, Hu Z, Beck AP, Delahaye F, et al. Apc inactivation, but not obesity, synergizes with Pten deficiency to drive intestinal stem cell-derived tumorigenesis. Endocr Relat Cancer (2017) 24:253-65. doi: 10.1530/ERC-16-0536

37. Huffman DM, Farias Quipildor G, Mao K, Zhang X, Wan J, Apontes P, et al. Central insulin-like growth factor-1 (IGF-1) restores whole-body insulin action in a model of age-related insulin resistance and IGF-1 decline. Aging Cell (2016) 15:181-6. doi: 10.1111/acel.12415

38. Beutheu Youmba S, Belmonte L, Galas L, Boukhettala N, Bole-Feysot C Dechelotte $\mathrm{P}$, et al. Methotrexate modulates tight junctions through NFkappaB, MEK, and JNK pathways. J Pediatr Gastroenterol Nutr. (2012) 54:463-70. doi: 10.1097/MPG.0b013e318247240d

39. Cheadle GA, Costantini TW, Lopez N, Bansal V, Eliceiri BP, Coimbra R. Enteric glia cells attenuate cytomix-induced intestinal epithelial barrier breakdown. PLoS ONE (2013) 8:e69042. doi: 10.1371/journal.pone. 0069042

40. Tanaka H, Takechi M, Kiyonari H, Shioi G, Tamura A, Tsukita S. Intestinal deletion of Claudin-7 enhances paracellular organic solute flux and initiates colonic inflammation in mice. Gut (2015) 64:1529-38. doi: 10.1136/gutjnl-2014-308419

41. Cani PD, Possemiers S, Van De Wiele T, Guiot Y, Everard A, Rottier O, et al. Changes in gut microbiota control inflammation in obese mice through a mechanism involving GLP-2-driven improvement of gut permeability. Gut (2009) 58:1091-103. doi: 10.1136/gut.2008.165886

42. Yilmaz OH, Katajisto P, Lamming DW, Gultekin Y, Bauer-Rowe KE, Sengupta $\mathrm{S}$, et al. mTORC1 in the paneth cell niche couples intestinal stem-cell function to calorie intake. Nature (2012) 486:490-5. doi: 10.1038/nature 11163

43. Tomasetti C, and Vogelstein B. Cancer etiology. Variation in cancer risk among tissues can be explained by the number of stem cell divisions. Science (2015) 347:78-81. doi: 10.1126/science.1260825 
44. Augenlicht LH. Environmental impact on intestinal stem cell functions in mucosal homeostasis and tumorigenesis. J Cell Biochem. (2017) 118:943-52. doi: $10.1002 /$ jcb. 25719

45. Flegal KM, Carroll MD, Ogden CL, Curtin LR. Prevalence and trends in obesity among US adults, 1999-2008. JAMA (2010) 303:235-41. doi: 10.1001/jama.2009.2014

46. Flegal KM, Carroll MD, Kit BK, Ogden CL. Prevalence of obesity and trends in the distribution of body mass index among US adults, 1999-2010. JAMA (2012) 307:491-7. doi: 10.1001/jama.2012.39

47. Wang YC, McPherson K, Marsh T, Gortmaker SL, Brown M. Health and economic burden of the projected obesity trends in the USA and the UK. Lancet (2011) 378:815-25. doi: 10.1016/S0140-6736(11)60814-3

48. Mirkin G. Walnuts and serum lipids. N Engl J Med. (1993) 329:58. doi: 10.1056/NEJM199307293290513

49. Wu L, Piotrowski K, Rau T, Waldmann E, Broedl UC, Demmelmair $\mathrm{H}$, et al. Walnut-enriched diet reduces fasting non-HDL-cholesterol and apolipoprotein B in healthy Caucasian subjects: a randomized controlled cross-over clinical trial. Metabolism (2014) 63:382-91. doi: 10.1016/j.metabol.2013.11.005

50. Chamberland JP, Moon HS. Down-regulation of malignant potential by alpha linolenic acid in human and mouse colon cancer cells. Fam Cancer (2015) 14:25-30. doi: 10.1007/s10689-014-9762-z

51. Jahanbani R, Ghaffari SM, Salami M, Vahdati K, Sepehri H, Sarvestani NN, et al. Antioxidant and anticancer activities of walnut (Juglans regia L.) protein hydrolysates using different proteases. Plant Foods Hum Nutr. (2016) 71:4029. doi: 10.1007/s11130-016-0576-z

52. Lee J, Kim YS, Heo SC, Lee KL, Choi SW, Kim Y. Walnut phenolic extract and its bioactive compounds suppress colon cancer cell growth by regulating colon cancer stemness. Nutrients (2016) 8:E439. doi: 10.3390/nu8070439

53. Austad SN, Fischer KE. Sex differences in lifespan. Cell Metab. (2016) 23:1022-33. doi: 10.1016/j.cmet.2016.05.019

54. Bardou M, Barkun AN, Martel M. Obesity and colorectal cancer. Gut (2013) 62:933-47. doi: 10.1136/gutjnl-2013-304701

55. Bingham S, Riboli E. Diet and cancer-the European prospective investigation into cancer and nutrition. Nat Rev Cancer (2004) 4:206-15. doi: $10.1038 / \mathrm{nrcl} 298$

56. Delellis Henderson K, Duan L, Sullivan-Halley J, Ma H, Clarke CA, Neuhausen SL, et al. Menopausal hormone therapy use and risk of invasive colon cancer: the California teachers study. Am J Epidemiol. (2010) 171:41525. doi: 10.1093/aje/kwp434

57. Allott EH, Hursting SD. Obesity and cancer: mechanistic insights from transdisciplinary studies. Endocr Relat Cancer (2015) 22:R365-86. doi: 10.1530/ERC-15-0400

58. Cambien B, Richard-Fiardo P, Karimdjee BF, Martini V, Ferrua B, Pitard $\mathrm{B}$, et al. CCL5 neutralization restricts cancer growth and potentiates the targeting of PDGFRbeta in colorectal carcinoma. PLoS ONE (2011) 6:e28842. doi: 10.1371/journal.pone.0028842

59. Chang LY, Lin YC, Mahalingam J, Huang CT, Chen TW, Kang CW, et al. Tumor-derived chemokine CCL5 enhances TGF-beta-mediated killing of CD8(+) $\mathrm{T}$ cells in colon cancer by T-regulatory cells. Cancer Res. (2012) 72:1092-102. doi: 10.1158/0008-5472.CAN-11-2493

60. Kan JY, Wu DC, Yu FJ, Wu CY, Ho YW, Chiu YJ, et al. Chemokine (C-C Motif) ligand 5 is involved in tumor-associated dendritic cell-mediated colon cancer progression through non-coding RNA MALAT-1. J Cell Physiol. (2015) 230:1883-94. doi: 10.1002/jcp.24918

61. Navarro SL, Neuhouser ML, Cheng TD, Tinker LF, Shikany JM, Snetselaar $\mathrm{L}$, et al. The interaction between dietary fiber and fat and risk of colorectal cancer in the women's health initiative. Nutrients (2016) 8:E779. doi: 10.3390/nu8120779

62. Bailie L, Loughrey MB, Coleman HG. Lifestyle risk factors for serrated colorectal polyps: a systematic review and meta-analysis. Gastroenterology (2017) 152:92-104. doi: 10.1053/j.gastro.2016.09.003

63. Song M, Wu K, Meyerhardt JA, Ogino S, Wang M, Fuchs CS, et al. Fiber intake and survival after colorectal cancer diagnosis. JAMA Oncol. (2018) 4:71-9. doi: 10.1001/jamaoncol.2017.3684

64. Diallo A, Deschasaux M, Latino-Martel P, Hercberg S, Galan P, Fassier P, et al. Red and processed meat intake and cancer risk: results from the prospective NutriNet-Sante cohort study. Int J Cancer (2018) 142:230-7. doi: 10.1002/ijc.31046

65. Zhao Z, Feng Q, Yin Z, Shuang J, Bai B, Yu P, et al. Red and processed meat consumption and colorectal cancer risk: a systematic review and metaanalysis. Oncotarget (2017) 8:83306-14. doi: 10.18632/oncotarget.21466

66. Sun Z, Liu L, Wang PP, Roebothan B, Zhao J, Dicks E, et al. Association of total energy intake and macronutrient consumption with colorectal cancer risk: results from a large population-based case-control study in Newfoundland and Labrador and Ontario, Canada. Nutr J. (2012) 11:18. doi: 10.1186/1475-2891-11-18

67. Vargas AJ, and Thompson PA. Diet and nutrient factors in colorectal cancer risk. Nutr Clin Pract. (2012) 27:613-23. doi: 10.1177/0884533612454885

68. Harris DL, Washington MK, Hood DB, Roberts LJ II, Ramesh A. Dietary fat-influenced development of colon neoplasia in Apc Min mice exposed to benzo(a)pyrene. Toxicol Pathol. (2009) 37:938-46. doi: 10.1177/0192623309351722

69. Enos RT, Velazquez KT, McClellan JL, Cranford TL, Nagarkatti M, Nagarkatti PS, et al. High-fat diets rich in saturated fat protect against azoxymethane/dextran sulfate sodium-induced colon cancer. Am J Physiol Gastrointest Liver Physiol. (2016) 310:G906-19. doi: 10.1152/ajpgi.00345.2015

70. Sangiorgi E, and Capecchi MR. Bmil is expressed in vivo in intestinal stem cells. Nat Genet. (2008) 40:915-20. doi: 10.1038/ng.165

71. Barker N, Ridgway RA, Van Es JH, Van De Wetering M, Begthel H, Van Den Born M, et al. Crypt stem cells as the cells-of-origin of intestinal cancer. Nature (2009) 457:608-11. doi: 10.1038/nature07602

72. Powell AE, Vlacich G, Zhao ZY, McKinley ET, Washington MK, Manning $\mathrm{HC}$, et al. Inducible loss of one Apc allele in Lrig1-expressing progenitor cells results in multiple distal colonic tumors with features of familial adenomatous polyposis. Am J Physiol Gastrointest Liver Physiol. (2014) 307:G16-23. doi: 10.1152/ajpgi.00358.2013

73. Nalapareddy K, Nattamai KJ, Kumar RS, Karns R, Wikenheiser-Brokamp KA, Sampson LL, et al. Canonical Wnt signaling ameliorates aging of intestinal stem cells. Cell Rep. (2017) 18:2608-21. doi: 10.1016/j.celrep.2017.02.056

74. Augenlicht L. Hidden effects of mouse chow. Science (2014) 346:710. doi: $10.1126 /$ science. 346.6210 .710 -a

Conflict of Interest Statement: The authors declare that the research was conducted in the absence of any commercial or financial relationships that could be construed as a potential conflict of interest.

Copyright (c) 2018 Guan, Tabrizian, Novaj, Nakanishi, Rosenberg and Huffman. This is an open-access article distributed under the terms of the Creative Commons Attribution License (CC BY). The use, distribution or reproduction in other forums is permitted, provided the original author(s) and the copyright owner are credited and that the original publication in this journal is cited, in accordance with accepted academic practice. No use, distribution or reproduction is permitted which does not comply with these terms. 